\title{
Erratum to: Influence of acute or chronic administration of ovarian hormones on the effects of desipramine in the forced swim test in female rats
}

\author{
Aparna Shah • Alan Frazer
}

Published online: 5 April 2014

(C) Springer-Verlag Berlin Heidelberg 2014

\section{Erratum to: Psychopharmacology}

DOI 10.1007/s00213-014-3510-9

The original version of this article inadvertently contained a mistake.

The first paragraph of the chronic study section in the Results should read "Hormones were administered via subcutaneous pellets containing E2 and P (21-day release). The dose of $\mathrm{P}$ (10 mg/pellet) was determined based on a preliminary study where serum levels of $\mathrm{P}$ as tested by RIA were $28.0 \pm$ $4.64 \mathrm{ng} / \mathrm{ml}$ on day 3 and $23.5 \pm 3.96 \mathrm{ng} / \mathrm{ml}$ on day 8 (unpublished data provided by Dr. Saloua Benmansour, UTHSCSA and Dr. Andrea Gore, UT Austin), suggesting maintenance of a constant serum level higher than baseline values".

The online version of the original article can be found at http://dx.doi.org/ 10.1007/s00213-014-3510-9.

A. Shah $(\bowtie) \cdot$ A. Frazer

Department of Pharmacology and Center for Biomedical

Neuroscience, University of Texas Health Science Center at San

Antonio, 7703 Floyd Curl Drive, Mail Code 7764, San Antonio,

TX 78229-3900, USA

e-mail: shahap@uthscsa.edu

\section{A. Frazer}

South Texas Veterans Health Care System (STVHCS), Audie L.

Murphy Division, San Antonio, TX, USA 